\title{
Effect of multiple-micronutrient supplementation on maternal nutrient status, infant birth weight and gestational age at birth in a low-income, multi-ethnic population
}

\author{
Louise Brough $^{1}$, Gail A. Rees ${ }^{2}$, Michael A. Crawford ${ }^{3}$, R. Hugh Morton ${ }^{1}$ and Edgar K. Dorman ${ }^{4}$ \\ ${ }^{1}$ Institute of Food Nutrition and Human Health, Massey University, Palmerston North, New Zealand, Massey University, Private \\ Bag 11222, Palmerston North, New Zealand \\ ${ }^{2}$ School of Biological Sciences, University of Plymouth, Drake Circus, Plymouth PL4 8AA, UK \\ ${ }^{3}$ Institute of Brain Chemistry and Human Nutrition, London Metropolitan University, 166-220 Holloway Road, \\ London N7 8DB, UK \\ ${ }^{4}$ Homerton University Hospital, Homerton Row, London E9 6SR, UK
}

(Received 16 September 2009 - Revised 5 January 2010 - Accepted 9 February 2010 - First published online 23 April 2010)

Poor nutrient intake during pregnancy can adversely affect both infant and maternal health. The aim was to investigate the efficacy of multiple-micronutrient supplementation during pregnancy in a socially deprived population in the developed world. We conducted a randomised, double-blind, placebo-controlled trial of multiple-micronutrient supplementation including $20 \mathrm{mg} \mathrm{Fe}$ and $400 \mu \mathrm{g}$ folic acid, from the first trimester of pregnancy in 402 mothers, in East London, UK. Nutrient status was measured at recruitment, and at 26 and 34 weeks of gestation. Infants were weighed at birth. At recruitment the prevalence of anaemia was $13 \%$, vitamin D insufficiency $72 \%$, thiamin deficiency $12 \%$ and folate deficiency $5 \%$, with no differences between groups. Only $39 \%$ of women completed the study; rates of non-compliance were similar in both groups Intention-to-treat analysis showed that participants receiving treatment had higher mean $\mathrm{Hb}$ at 26 weeks of gestation (110 (SD 10) v.108 (SD 10) $\mathrm{g} / \mathrm{l} ; P=0.041)$ and 34 weeks of gestation (113 (SD 12) $v .109$ (SD 10) $\mathrm{g} / \mathrm{l} ; P=0.003$ ) and packed cell volume concentrations at 26 weeks of gestation $(0.330$ (SD 0.025) v. 0.323 (SD 0.026) $1 / 1 ; P=0.011)$ and 34 weeks of gestation $(0.338$ (SD 0.029) v. 0.330 (SD 0.028) $1 / 1 ; P=0.014)$ compared with controls. Analysis of compliant women showed supplemented women had higher median concentrations of serum ferritin, erythrocyte folate and 25-hydroxyvitamin D later in gestation than controls. In the compliant subset ( $n$ 149), placebo mothers had more small-for-gestational age (SGA) infants (eight SGA $v$. thirteen; $P=0.042$ ) than treatment mothers. Baseline micronutrient deficiencies were common; the multiple-micronutrient supplement was well-tolerated and improved nutrient status. Multiple-micronutrient supplements from early pregnancy may be beneficial and larger studies are required to assess impact on birth outcomes and infant development.

Multiple-micronutrient supplementation: Low-income populations: Multi-ethnic populations: Micronutrient status

It is well established that nutrient intake during pregnancy plays a significant role in maternal and child health ${ }^{(1)}$. Hackney in the East End of London has a substantial immigrant population with high levels of social and economic deprivation, mirroring many large cities throughout the developed world. Deprivation is associated with poor birth outcomes such as low birth weight (LBW), preterm birth and intra-uterine growth restriction ${ }^{(2)}$. Previous research here has demonstrated poor micronutrient intakes and status, including $\mathrm{Fe}$, folate and thiamin, which have been associated with such adverse pregnancy outcomes ${ }^{(3-5)}$.

The most recent Cochrane review ${ }^{(6)}$ states that there is insufficient evidence to suggest that multiple-micronutrient supplementation is any more effective at improving birth outcome than $\mathrm{Fe}$ and folic acid supplements alone. However, the authors concede that further research is required due to a lack of well-controlled studies in this area. Furthermore, many studies are now over 20 years old and more recent studies have been in developing countries, making it difficult to extrapolate the results to industrialised populations.

An observational study of multiple-micronutrient supplement use in early pregnancy amongst low-income women ( $n$ 1430) in the USA found supplement users had a twofold reduced risk of preterm birth and LBW; beginning supplement use in the first trimester led to a greater reduction in risk compared with the second trimester ${ }^{(7)}$. However, this was not a randomised, controlled trial, and women choosing to use supplements may have had an intrinsically lower risk of poor birth outcome compared with non-users. A small randomised controlled trial in France ( $n$ 65) showed that women receiving multiple-micronutrient supplements from about 14 weeks of gestation had improved micronutrient

Abbreviations: LBW, low birth weight; PCV, packed cell volume; RNI, reference nutrient intake; SGA, small for gestational age; TDP, thiamin diphosphate. 
status and gave birth to infants with a mean birth weight $10 \%$ higher than those receiving placebo ${ }^{(8)}$. Although the French results are promising, the results from such a small sample size require corroboration.

This present study builds on previous research and is the first double-blind, randomised and controlled trial of multiplemicronutrient supplementation from the first trimester of pregnancy in a socially deprived, multi-ethnic population within a developed country. We assessed the effect of such supplementation on maternal nutrient status, namely $\mathrm{Fe}$, folate, thiamin and vitamin $\mathrm{D}$, and infant birth weight and gestational age at birth.

\section{Subjects and methods}

\section{Participants}

Between June 2002 and May 2004 women were recruited at their booking (first) appointment from the Homerton Hospital antenatal clinic and two community clinics in the borough of Hackney in East London, as previously described ${ }^{(9)}$. Volunteers were aged 16 years or older with a singleton pregnancy. Exclusion criteria included a gestation of greater than 13 weeks of gestation, chronic disease or use of micronutrient supplements (excluding folic acid and Fe). The present study was conducted according to the guidelines laid down in the Declaration of Helsinki and all procedures involving human subjects were approved by the East London and the City Health Authority research ethics committee. Informed, written consent was obtained from all participants; non-English speaking women were only recruited if a suitable advocate was available.

\section{Intervention}

Participants were randomised to receive either multiple-micronutrient supplements (Table 1), known as Pregnacare, or a visually identical placebo comprising starch with an iron oxide coating. All tablets were provided by Vitabiotics (London, UK) and packaged to allow double blinding. Only Vitabiotics knew the code and it was not broken until statistical analysis had been completed. Each participant was

Table 1. Micronutrient composition of treatment tablets

\begin{tabular}{lr}
\hline Micronutrient & Dose per tablet \\
\hline$\beta$-Carotene & $3 \mathrm{mg}$ \\
Thiamin (as thiamin mononitrate, $3.6 \mathrm{mg})$ & $3 \mathrm{mg}$ \\
Riboflavin & $2 \mathrm{mg}$ \\
Niacin (as nicotinamide) & $20 \mathrm{mg}$ \\
Vitamin $\mathrm{B}_{6}$ (as pyridoxine $\mathrm{HCl}$ ) & $10 \mathrm{mg}$ \\
Vitamin $\mathrm{B}_{12}$ (as cyanocobalamin) & $6 \mu \mathrm{g}$ \\
Folic acid & $400 \mu \mathrm{g}$ \\
Vitamin C (as ascorbic acid, $73 \mathrm{mg}$ ) & $70 \mathrm{mg}$ \\
Vitamin D (as cholecalciferol, $200 \mathrm{IU})$ & $5 \mu \mathrm{g}$ \\
Vitamin E (as D- $\alpha$-tocopheryl acid succinate, $21 \mathrm{mg})$ & $20 \mathrm{mg}$ \\
Vitamin K & $70 \mu \mathrm{g}$ \\
Fe (as ferrous fumarate, $63.3 \mathrm{mg}$ ) & $20 \mathrm{mg}$ \\
Zn (as zinc sulfate $\left.\mathrm{H}_{2} \mathrm{O}, 41 \mathrm{mg}\right)$ & $15 \mathrm{mg}$ \\
Mg (as magnesium hydroxide, $372 \mathrm{mg})$ & $150 \mathrm{mg}$ \\
lodine (as potassium iodide, $183 \mu \mathrm{g}$ ) & $140 \mu \mathrm{g}$ \\
Cu (as copper sulfate $\left.\mathrm{H}_{2} \mathrm{O}, 2.8 \mathrm{mg}\right)$ & $1 \mathrm{mg}$ \\
\hline
\end{tabular}

instructed to take one tablet daily with food and plenty of water from recruitment until her baby was delivered. Women not using folic acid were also given $400 \mu \mathrm{g}$ folic acid to take daily until 12 weeks of gestation.

\section{Anthropometric, demographic and ethnic data}

At booking, height was ascertained to the nearest $1 \mathrm{~cm}$ and weight was measured, without shoes in light clothing, to the nearest $1 \mathrm{~kg}$. Obstetric and medical information was available from hospital notes. Estimated date of delivery and gestational age at booking were determined by a qualified sonographer using an ultrasound scan. Participants reported over fifty different ethnicities; to aid data analysis these were reduced to five ethnic groups: African, Asian, Caucasian, West Indian and Other.

\section{Follow-up and compliance}

Participants were followed up at routine appointments at 20, 26 and 34 weeks of gestation. Subjects were questioned about frequency of supplement use and more tablets were provided as required. If supplement use had ceased, information was obtained regarding length and frequency of use together with reason for cessation.

\section{Nutrient status}

$\mathrm{Hb}$ and packed cell volume (PCV) were routinely determined on EDTA-stabilised whole blood samples, using a Coulter STKS analyser (Beckman Coulter, Brea, CA, USA), thus data were available for the majority of participants at recruitment and 26-week and 34-week visits. Serum ferritin and erythrocyte folate were measured using a DPC Immulite 2000 analyser (DPC, Los Angeles, CA, USA), a fully automated immunoassay analyser. Measures were made on the majority of the samples at booking, but only for compliant participants at 26-week and 34-week visits.

An additional blood sample was taken from compliant participants; lithium-heparin stabilised whole blood was spun and packed erythrocytes and plasma were stored at $-70^{\circ} \mathrm{C}$. Thiamin diphosphate (TDP) in the erythrocytes was determined directly using HPLC coupled with a spectrofluorimeter and reagent kit (Chromsystems, Manchester, UK); TDP in whole blood was then calculated. TDP was measured in a subset of samples at booking and 34 weeks of gestation only. Plasma was used to measure 25-hydroxyvitamin $\mathrm{D}_{3}$ directly using HPLC with UV detection; internal standards from Chromsystems (Manchester) were used for HPLC calibration. Vitamin D was assessed at booking, and at 26-week and 34-week appointments. The season of sample collection was defined as summer (April to September) and winter (October to March). For technical reasons we were unable to analyse all samples for vitamin D (especially at 26 weeks); hence the low numbers of data. All analysis was performed at the Homerton Hospital pathology laboratory (London, UK), except for TDP which was analysed at Epsom Hospital (Epsom, Surrey, UK). 


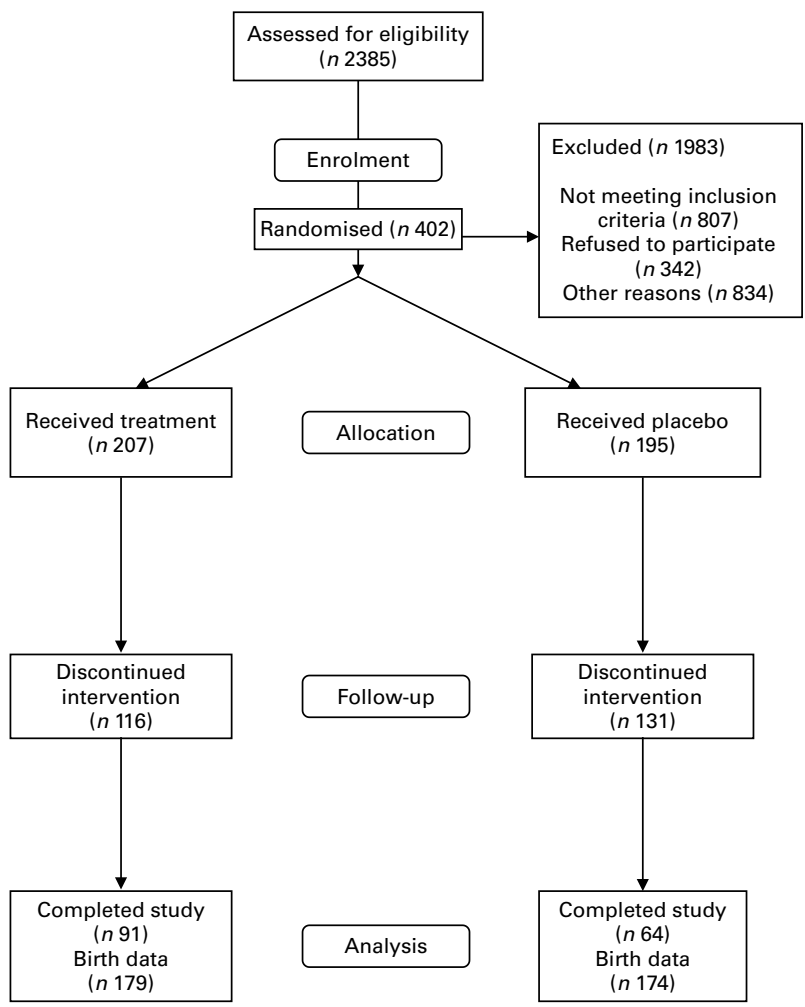

Fig. 1. Flow chart showing treatment allocation and participant compliance.

\section{Obstetric data}

Obstetric and medical information was available from hospital notes. Immediately after birth, infant weight was determined to the nearest $10 \mathrm{~g}$ using weighing scales and the infant's head circumference was measured using a measuring tape to the nearest $0.5 \mathrm{~cm}$. All measures were determined by a midwife. Infants weighing less than $2500 \mathrm{~g}$ at birth were defined as LBW. Preterm birth was defined as infants born before 37 weeks of gestation (based on ultrasound scan). Centiles were calculated based on birth weight for gestational age using sex-specific, British 1990 growth reference data provided by the Child Growth Foundation (London, UK). Infants below the 10th centile of weight for gestational age were defined as small for gestational age (SGA).

\section{Statistical analysis}

Statistical analyses were carried out using SPSS 15.0 for Windows (SPSS, Inc., Chicago, IL, USA). Normality of data was assessed using the Kolmogorov-Smirnoff test and visual inspection of Q-Q plots. Normally distributed data are presented as means with standard deviations; non-normally distributed data are expressed as medians with interquartile ranges. Differences between treatment groups were assessed using independent $t$ tests (two-tailed; parametric) or the Mann-Whitney $U$ test (two-tailed; non-parametric). Categorical associations were examined using $\chi^{2}$. Intention-to-treat analysis was used for measures of $\mathrm{Hb}$ and PCV. However, measures of serum ferritin, erythrocyte folate, thiamin and 25-hydroxyvitamin $\mathrm{D}_{3}$ were only available for compliant participants at 26 and 34 weeks of gestation; thus analysis of these represents a subset. Spearman's rank correlation coefficient was used to determine associations between two numerical variables; potential correlations were verified using scatter plots.

Nutrient data which were not normally distributed were transformed logarithmically before analysis to approximate normal distribution. The data were analysed for an effect of supplement and time by repeated-measures ANOVA

Table 2. Description of 402 participants at booking by treatment group

\begin{tabular}{|c|c|c|c|c|}
\hline \multirow[t]{2}{*}{ Treatment group... } & \multicolumn{2}{|c|}{ Treatment (n 207) } & \multicolumn{2}{|r|}{ Placebo (n 195) } \\
\hline & $n$ & $\%$ of treatment group & $n$ & $\%$ of treatment group \\
\hline \multicolumn{5}{|l|}{ Ethnicity } \\
\hline African & 62 & 30 & 49 & 25 \\
\hline Asian & 18 & 9 & 24 & 12 \\
\hline Caucasian & 79 & 38 & 76 & 39 \\
\hline West Indian & 37 & 18 & 29 & 15 \\
\hline Other & 11 & 5 & 17 & 9 \\
\hline \multicolumn{5}{|l|}{ Parity } \\
\hline Nulliparous & 109 & 53 & 99 & 51 \\
\hline Parous & 98 & 47 & 96 & 49 \\
\hline \multicolumn{5}{|l|}{ Age (years) } \\
\hline Mean & & $28 \cdot 4$ & & $27 \cdot 9$ \\
\hline SD & & $5 \cdot 86$ & & $6 \cdot 20$ \\
\hline \multicolumn{5}{|l|}{ Height (m) } \\
\hline Mean & & 1.64 & & 1.64 \\
\hline SD & & 0.07 & & 0.07 \\
\hline \multicolumn{5}{|l|}{ Weight (kg) } \\
\hline Median & & $68 \cdot 0$ & & $67 \cdot 0$ \\
\hline Interquartile range & & 60,78 & & 60,77 \\
\hline \multicolumn{5}{|l|}{ BMI $\left(\mathrm{kg} / \mathrm{m}^{2}\right)$} \\
\hline Median & & $25 \cdot 5$ & & $24 \cdot 7$ \\
\hline Interquartile range & & $22 \cdot 1,28 \cdot 7$ & & $22 \cdot 3,28 \cdot 5$ \\
\hline \multicolumn{5}{|c|}{ Gestation at booking (d) } \\
\hline Median & & 84 & & 84 \\
\hline Interquartile range & & 77,87 & & 77,88 \\
\hline
\end{tabular}


Table 3. Reasons for non-completion of the study according to treatment group

\begin{tabular}{|c|c|c|c|}
\hline & Treatment & Placebo & Total \\
\hline Decided not continue with study & 24 & 25 & 49 \\
\hline $\begin{array}{l}\text { Husband, partner or family } \\
\text { advised against }\end{array}$ & 9 & 8 & 17 \\
\hline Changed mind or concerned & 10 & 6 & 16 \\
\hline $\begin{array}{l}\text { Decided to take micronutrient } \\
\text { supplement }\end{array}$ & 2 & 8 & 10 \\
\hline Does not want placebo & 3 & 3 & 6 \\
\hline Disliked formulation of tablets & 16 & 15 & 31 \\
\hline Too large & 9 & 13 & 22 \\
\hline Disliked smell & 5 & 0 & 5 \\
\hline Disliked taste & 2 & 2 & 4 \\
\hline Reported side effects & 25 & 28 & 53 \\
\hline Nausea or vomiting & 17 & 18 & 35 \\
\hline Increased appetite & 2 & 1 & 3 \\
\hline Stomach ache & 0 & 2 & 2 \\
\hline Constipated & 2 & 0 & 2 \\
\hline Headache or dizziness & 1 & 0 & 1 \\
\hline Rash & 0 & 1 & 1 \\
\hline Shiver & 0 & 1 & 1 \\
\hline Diarrhoea & 0 & 1 & 1 \\
\hline Increased urination & 1 & 0 & 0 \\
\hline Tired & 0 & 1 & 1 \\
\hline Unwell - not specified & 1 & 2 & 3 \\
\hline Valid medical reason & 17 & 18 & 35 \\
\hline Hyperemesis & 8 & 10 & 18 \\
\hline Miscarried or termination & 6 & 5 & 11 \\
\hline Twins & 2 & 0 & 2 \\
\hline Other & 1 & 3 & 4 \\
\hline Reason beyond participants' control & 34 & 45 & 79 \\
\hline $\begin{array}{l}\text { Wrongly advised to cease } \\
\text { by health professional }\end{array}$ & 3 & 4 & 7 \\
\hline $\begin{array}{l}\text { Given other medication (not } \\
\text { contraindicated) }\end{array}$ & 3 & 6 & 9 \\
\hline Patient otherwise unwell & 4 & 2 & 8 \\
\hline $\begin{array}{l}\text { Moved away or unable } \\
\text { to contact }\end{array}$ & 8 & 5 & 13 \\
\hline $\begin{array}{l}\text { Forgot to take or } \\
\text { lost supplements }\end{array}$ & 15 & 26 & 41 \\
\hline Family trauma & 1 & 2 & 3 \\
\hline Total & 116 & 131 & 267 \\
\hline
\end{tabular}

using the general linear model. Post hoc comparisons with Bonferroni's correction were used to test for specific comparisons between time-points and between the two groups (supplement and placebo) at each time-point.

\section{Results}

\section{Participants}

Of the 2385 women identified as suitable based on general practitioner referral letter, 402 agreed to participate (Fig. 1) and 342 refused to participate. The remainder either did not present for the first antenatal appointment ( $n$ 365), were missed when the researcher was with another participant ( $n$ 216), were found not to meet the inclusion criteria ( $n$ 807) or were non-English speaking and no advocate was available (n 253). Participants were aged between 16 and 42 years with a gestational age at recruitment between 35 and $125 \mathrm{~d}$ (Table 2). Subsequent to recruitment, thirteen participants were found by ultrasound scan to have a gestation of greater than 13 weeks $\left(13^{+1}\right.$ to $\left.17^{+6}\right)$; they remained in the study and the final analysis, as their inclusion afforded little difference in the nutrient data. Two women were carrying twins and were removed from the study. Of the recruits, 207 $(51 \%)$ were allocated to the treatment group and $195(49 \%)$ to the placebo group. There were no significant differences in age, height, weight, BMI or parity regarding treatment group allocation.

\section{Compliance}

Only $39 \%$ of participants remained compliant for the duration of the study. Reasons for non-compliance were many and varied (Table 3). Motivation was a substantial problem; $20 \%$ of non-compliers decided that they no longer wanted to take part in the study and $17 \%$ either forgot to take their tablets or lost them. Of non-compliers, $5 \%$ moved away, reflecting the highly mobile population and $14 \%$ of non-compliers stopped for medical reasons such as a high-risk pregnancy. Despite the study being widely advertised amongst local health professionals, $9 \%$ of non-compliers were advised to cease the supplements for reasons which did not preclude them, such as nausea, low $\mathrm{Hb}$ or prescription of Fe supplements.

Participants were regarded as compliers if they reported taking five or more tablets per week until the 34-week appointment (median 240 (interquartile range 238, 242) d) or 26-week appointment (median 184 (interquartile range 182, 187) d) if delivery was before 34 weeks of gestation. Participants receiving the treatment were more likely to be compliers and those receiving placebo were less likely to be compliers $\left(P=0.022 ; \chi^{2}\right.$ test $)$. Compliers were on average significantly older $(29.1$ v. 27.6 years; $P=0.016 ; t$ test) and had a greater median gestational age at booking $(85$ v. $83 \mathrm{~d} ; P=0.002$, Mann-Whitney $U$ test) than non-compliers; however, there were no differences at recruitment regarding nutritional status for compliers compared with non-compliers.

\section{Infant birth data}

Data were available for 353 live-born singleton infants. Using intention-to-treat analysis there were no significant differences between treatment and placebo infants regarding mean birth weight, gestational age at birth or number of infants defined as SGA (Table 4). However, considering only compliant mothers, the women in the placebo group were significantly more likely to have an SGA infant compared with those in the treatment group $\left(P=0.042 ; \chi^{2}\right)$. On removing those participants who were recruited at greater than 13 weeks of gestation the significance no longer remained. However, it could be argued that the 13-week recruitment criterion is an arbitrary cut-off and that the supplement may also be beneficial for women just over 13 weeks of gestation.

\section{Nutrient status}

Using intention-to-treat analysis, repeated-measures ANOVA showed a significant overall difference in $\mathrm{Hb}$ concentrations (Table 5) by treatment $(F(1,285)=207.55 ; P=0.033)$ and gestation $(F(2,570)=4.59 ; P<0.001)$ and an interaction between treatment and gestation $(F(2,570)=4 \cdot 89 ; P=0 \cdot 012)$. Post hoc analysis showed that $\mathrm{Hb}$ concentrations were significantly lower in the placebo group compared with the treatment group at 26 weeks of gestation $(P=0.041)$ and 34 weeks of 
Table 4. Description of birth outcome by treatment group

\begin{tabular}{|c|c|c|c|c|}
\hline \multirow[b]{2}{*}{ Treatment group... } & \multicolumn{2}{|c|}{ All live births } & \multicolumn{2}{|c|}{ Compliers only } \\
\hline & Treatment & Placebo & Treatment & Placebo \\
\hline Number of live born infants & 179 & 174 & 88 & 61 \\
\hline \multicolumn{5}{|l|}{ Delivery details } \\
\hline Low birth weight $(<2500 \mathrm{~g})(n)$ & 13 & 8 & 6 & \\
\hline Preterm ( $<37$ weeks) $(n)$ & 9 & 8 & 6 & 3 \\
\hline Small for gestational age $(n) \dagger$ & 30 & 31 & $8^{*}$ & $13^{*}$ \\
\hline \multicolumn{5}{|l|}{ Birth weight $(\mathrm{g})$} \\
\hline Mean & 3240 & 3233 & 3270 & 3141 \\
\hline SD & 539 & 519 & 591 & 485 \\
\hline \multicolumn{5}{|l|}{ Gestation at birth (d) } \\
\hline Median & 280 & 278 & 279 & 275 \\
\hline Interquartile range & 271,286 & 272,285 & 273,285 & 271,281 \\
\hline \multicolumn{5}{|l|}{ Head circumference $(\mathrm{cm})$} \\
\hline Mean & 33.7 & 33.9 & 33.9 & 33.8 \\
\hline SD & 1.5 & 1.6 & 1.4 & 1.7 \\
\hline
\end{tabular}

gestation $(P=0 \cdot 003)$. There was also an overall difference in PCV concentrations with gestation $(F(2,570)=169.54$; $P<0.001)$ and treatment $(F(1,285)=5.04 ; P=0.025)$, but no interaction between gestation and treatment $(F(2,570)=2 \cdot 29$; $P=0 \cdot 111)$. Post hoc analysis showed that PCV concentrations were significantly lower in the placebo group compared with the treatment group at 26 weeks of gestation $(P=0 \cdot 011)$ and 34 weeks of gestation $(P=0 \cdot 014)$.

Analysis of a compliant subset showed an overall difference in serum ferritin concentrations with gestation $(F(2,100)$ $=80.15 ; \quad P<0.001)$ and an interaction with treatment $(F(2,100)=5.38 ; P=0.008)$ but not for treatment alone $(F(1,50)=0 \cdot 1 ; P=0 \cdot 910)$. There was an overall difference in erythrocyte folate concentrations with gestation $(F(2,198)=22.13 ; \quad P<0.001)$ and treatment $(F(1,99)$ $=37.84 ; P<0.001)$ and an interaction between treatment and gestation $(F(2,198)=17.92 ; P<0 \cdot 001)$. Post hoc analysis showed that erythrocyte folate concentrations were significantly lower in the placebo group compared with the treatment group at booking $(P=0.026), 26$ weeks of gestation $(P<0.001)$ and 34 weeks of gestation $(P<0.001)$. Also there was an overall difference in vitamin $\mathrm{D}$ concentrations with gestation $(F(2,58)=7.26 ; P<0.002)$ and an interaction with treatment $(F(2,58)=5 \cdot 37 ; P=0 \cdot 009)$ but no effect for treatment alone $(F(1,29)=0.92 ; P=0 \cdot 347)$. Post hoc analysis showed that vitamin D concentrations were significantly lower in the placebo group compared with the treatment group at 26 weeks of gestation $(P=0 \cdot 018)$. Although mean TDP concentration was higher for those receiving treatment at 34 weeks of gestation, this was non-significant.

At recruitment $13 \%$ of women had anaemia $(\mathrm{Hb}<110 \mathrm{~g} / \mathrm{l})$, $16 \%$ low PCV concentrations $(<0.330$ litres per litre $)$ and $11 \%$ had low Fe stores (serum ferritin $<15 \mu \mathrm{g} / \mathrm{l})^{(10)}$. For all three measures of Fe status, the percentage of mothers with low status increased in later pregnancy; however, the increase was less amongst supplemented mothers. Of the women, seventeen $(5 \%)$ had marginal folate deficiency $(<345 \mathrm{nmol} / \mathrm{l})$ at booking, of which three had severe folate deficiency $(<230 \mathrm{nmol} / \mathrm{l})^{(11)}$. Folate status improved in later pregnancy, with only $1-2 \%$ with low status. At recruitment $12 \%$ of participants were thiamin deficient (TDP $<66.5 \mathrm{nmol} / \mathrm{l}$ ); by 34 weeks of gestation this increased to $32 \%$ in the placebo group compared with only $20 \%$ in the treatment group.

Of participants at recruitment, $72 \%$ had suboptimal 25hydroxyvitamin D concentrations $(<50 \mathrm{nmol} /)^{(12)}$. Median 25-hydroxyvitamin D concentrations varied by ethnicity $(P<0.001$; Kruskall-Wallis test $)$; Caucasians had the highest and Asians the lowest (Table 6). Due to the small sample sizes at 26 and 34 weeks, Caucasians were compared with non-Caucasians; Caucasians had a higher median vitamin D concentration at $26(P=0.035$; Mann-Whitney $U$ test $)$ but not 34 weeks of gestation. Median 25-hydroxyvitamin D levels were significantly greater in the summer (April to September) than the winter (October to March) $(P=0.006$; Mann-Whitney $U$ test) at 34 weeks of gestation, but not for the other occasions. At recruitment significant differences in median vitamin $\mathrm{D}$ concentrations were seen between the five ethnic groups for both summer $(P<0.001)$ and winter $(P=0.021$; Kruskall-Wallis test $)$. At 26 weeks Caucasians had a significantly higher median 25-hydroxyvitamin D concentration than non-Caucasians during the summer months $(P=0.018$; Mann-Whitney $U$ test $)$ but not the winter; there were no differences by ethnicity and season at 34 weeks of gestation. Vitamin D status improved as pregnancy progressed, with low status being greatest amongst those receiving placebo. The small number of samples analysed for vitamin D at 26 and 34 weeks made it difficult to investigate the interaction between treatment, season, ethnicity and gestation on vitamin D status in further detail.

\section{Nutrient status and birth outcome}

Gestational age at birth was weakly positively correlated with TDP concentrations at booking $(P=0.037 ; r \quad 0.152)$ and at 34 weeks of gestation $(P=0.006 ; r 0.342)$. Head circumference was weakly positively associated with erythrocyte folate at recruitment $(P=0.046 ; r 0 \cdot 111)$ and vitamin $\mathrm{D}$ concentrations at 34 weeks of gestation $(P=0.024 ; r 0.231)$. Serum ferritin at 26 weeks of gestation was weakly inversely correlated with head circumference $(P=0.021 ; r-0.237)$. 
Table 5. Maternal micronutrient status at recruitment, 26 and 34 weeks of gestation according to treatment group

\begin{tabular}{|c|c|c|c|c|c|c|c|c|c|c|c|c|c|c|c|c|}
\hline & \multirow[b]{3}{*}{ Cut-off } & \multicolumn{5}{|c|}{ Recruitment ( $n$ 402) } & \multicolumn{5}{|c|}{26 weeks } & \multicolumn{5}{|c|}{34 weeks } \\
\hline & & \multirow[b]{2}{*}{$n$} & \multirow[b]{2}{*}{ Mean } & \multirow[b]{2}{*}{ SD } & \multicolumn{2}{|c|}{$<$ Cut-off } & \multirow[b]{2}{*}{$n$} & \multirow[b]{2}{*}{ Mean } & \multirow[b]{2}{*}{ SD } & \multicolumn{2}{|c|}{$<$ Cut-off } & \multirow[b]{2}{*}{$n$} & \multirow[b]{2}{*}{ Mean } & \multirow[b]{2}{*}{ SD } & \multicolumn{2}{|c|}{$<$ Cut-off } \\
\hline & & & & & $n$ & $\%$ & & & & $n$ & $\%$ & & & & $n$ & $\%$ \\
\hline $\mathrm{Hb}(\mathrm{g} / \mathrm{l})$ & $<110 \mathrm{~g} / \mathrm{l}$ & & & & & & & & & & & & & & & \\
\hline Treatment group & & 201 & 120 & 10 & 26 & 13 & 176 & $110^{*}$ & 10 & 87 & 49 & 159 & $113 \dagger$ & 12 & 57 & 36 \\
\hline Placebo group & & 189 & $12 \cdot 0$ & $1 \cdot 0$ & 23 & 12 & 166 & $10 \cdot 8$ & $1 \cdot 0$ & 92 & 55 & 152 & $10 \cdot 9$ & $1 \cdot 0$ & 83 & 55 \\
\hline Packed cell volume (I//) & $<0.330 \mathrm{l} / \mathrm{l}$ & & & & & & & & & & & & & & & \\
\hline Treatment group & & 201 & 0.357 & 0.029 & 30 & 15 & 176 & $0.330 \ddagger$ & 0.025 & 95 & 54 & 159 & $0.338 \S$ & 0.029 & 66 & 42 \\
\hline Placebo group & & 189 & 0.357 & 0.030 & 31 & 16 & 166 & 0.323 & 0.026 & 103 & 62 & 152 & 0.330 & 0.028 & 80 & 53 \\
\hline Serum ferritint† & $<15 \mu \mathrm{g} / \mathrm{l}$ & & & & & & & & & & & & & & & \\
\hline Treatment group & & 180 & $46 \cdot 5$ & $27 \cdot 3,73 \cdot 8$ & 18 & 10 & 66 & $17 \cdot 0$ & $9 \cdot 8,29 \cdot 3$ & 28 & 42 & 55 & $16 \cdot 0$ & $9 \cdot 0,24 \cdot 0$ & 24 & 44 \\
\hline Placebo group & & 170 & 42.5 & $27 \cdot 0,74 \cdot 3$ & 21 & 12 & 40 & $10 \cdot 5$ & $7 \cdot 0,20 \cdot 8$ & 24 & 60 & 42 & $9 \cdot 0$ & $7 \cdot 0,15 \cdot 3$ & 30 & 71 \\
\hline Erythrocyte folate†† & $<345 \mathrm{nmol} / \mathrm{l}$ & & & & & & & & & & & & & & & \\
\hline Treatment group & & 190 & $897 \|$ & 624,1210 & 11 & 6 & 93 & 16869 & 1153,2063 & 1 & 1 & 71 & 15849 & 1187,2329 & 0 & \\
\hline Placebo group & & 177 & 798 & 571,1116 & 6 & 3 & 57 & 791 & 614,1094 & 1 & 2 & 52 & 756 & 531,1015 & 2 & 4 \\
\hline Thiamin diphosphate $(\mathrm{nmol} / \mathrm{l})$ & $<66.5 \mathrm{nmol} / \mathrm{l}$ & & & & & & & & & & & & & & & \\
\hline Treatment group & & 104 & 99.8 & 31.9 & 15 & 14 & - & - & - & - & & 41 & $100 \cdot 3$ & 41.6 & 8 & 20 \\
\hline Placebo group & & 104 & $100 \cdot 0$ & $30 \cdot 4$ & 10 & 10 & - & - & - & - & & 25 & 88.7 & $36 \cdot 8$ & 8 & 32 \\
\hline \multicolumn{17}{|l|}{ 25-Hydroxyvitamin D†† } \\
\hline Treatment group & $<50 \mathrm{nmol} / \mathrm{l}$ & 128 & 37.5 & $23 \cdot 0,54 \cdot 0$ & 87 & 68 & 34 & $51 \cdot 5^{\star \star}$ & $32 \cdot 0,84 \cdot 5$ & 15 & 44 & 61 & $67 \cdot 0$ & $46 \cdot 0,92 \cdot 0$ & 18 & 30 \\
\hline Placebo group & & 104 & 37.5 & $26 \cdot 0,48 \cdot 8$ & 79 & 76 & 16 & 37.0 & $15 \cdot 3,60 \cdot 8$ & 11 & 69 & 40 & 56.5 & $34.0,80.5$ & 18 & 45 \\
\hline Treatment group & $<25 \mathrm{nmol} / \mathrm{l}$ & 128 & & & 40 & 31 & 34 & & & 4 & 12 & 61 & & & 6 & 10 \\
\hline Placebo group & & 104 & & & 22 & 21 & 16 & & & 7 & 44 & 40 & & & 8 & 20 \\
\hline
\end{tabular}

Data were analysed for an effect of gestation and treatment using repeated-measures ANOVA. Values were significantly different from those of the placebo group (post hoc comparisons with Bonferroni's correction): ${ }^{*} P=0.041$, $\dagger P=0.003, \ddagger P=0.011, \S P=0.014, \| P=0.026$, १ $P<0.001,{ }^{* \star} P=0.018$.

t† Results expressed as median and interquartile range. 
Table 6. Maternal vitamin D status by season* and ethnicity

\begin{tabular}{|c|c|c|c|c|c|c|c|}
\hline & \multirow[b]{2}{*}{$n$} & \multicolumn{2}{|c|}{ Plasma vitamin $\mathrm{D}(\mathrm{nmol} / \mathrm{l})$} & \multicolumn{2}{|c|}{$\begin{array}{c}\text { Plasma } \\
\text { vitamin } \\
\mathrm{D}<50 \\
\mathrm{nmol} / \mathrm{l}\end{array}$} & \multicolumn{2}{|c|}{$\begin{array}{c}\text { Plasma } \\
\text { vitamin } \\
\mathrm{D}<25 \\
\mathrm{nmol} / \mathrm{l}\end{array}$} \\
\hline & & Median & Interquartile range & $n$ & $\% †$ & $n$ & $\% \dagger$ \\
\hline \multicolumn{8}{|l|}{ Booking } \\
\hline \multicolumn{8}{|l|}{ Winter } \\
\hline African & 26 & 37.5 & $24 \cdot 3,43 \cdot 3$ & 22 & 85 & 6 & 23 \\
\hline Asian & 16 & $18 \cdot 5$ & $9,39 \cdot 8$ & 14 & 88 & 8 & 50 \\
\hline Caucasian & 39 & $42 \cdot 0$ & 29,62 & 22 & 56 & 8 & 21 \\
\hline West Indian & 21 & $32 \cdot 0$ & $20 \cdot 5,55$ & 14 & 67 & 7 & 33 \\
\hline Other & 9 & $28 \cdot 0$ & $10 \cdot 5,41$ & 9 & 100 & 4 & 44 \\
\hline Total winter & 111 & $38 \cdot 0$ & 19,50 & 81 & 73 & 33 & 30 \\
\hline \multicolumn{8}{|l|}{ Summer } \\
\hline African & 32 & 35.5 & $24,45 \cdot 5$ & 26 & 81 & 9 & 28 \\
\hline Asian & 16 & $23 \cdot 5$ & $9,27 \cdot 8$ & 16 & 100 & 8 & 50 \\
\hline Caucasian & 49 & $50 \cdot 0$ & 36,70 & 24 & 49 & 6 & 12 \\
\hline West Indian & 14 & 48.5 & $26 \cdot 5,68 \cdot 3$ & 7 & 50 & 3 & 21 \\
\hline Other & 10 & 33.5 & $21.5,37.5$ & 10 & 100 & 3 & 30 \\
\hline Total summer & 121 & $37 \cdot 0$ & 25,52 & 83 & 69 & 29 & 24 \\
\hline \multicolumn{8}{|l|}{26 weeks } \\
\hline \multicolumn{8}{|l|}{ Winter } \\
\hline Caucasian & 8 & $72 \cdot 5$ & $43 \cdot 8,98 \cdot 3$ & 2 & 25 & 1 & 13 \\
\hline Non-Caucasian & 14 & $52 \cdot 2$ & $24 \cdot 5,76 \cdot 3$ & 6 & 43 & 3 & 21 \\
\hline Total winter & 22 & $61 \cdot 0$ & $30 \cdot 5,86 \cdot 3$ & 8 & 36 & 4 & 18 \\
\hline \multicolumn{8}{|l|}{ Summer } \\
\hline Caucasian & 14 & $55 \cdot 0$ & $34 \cdot 8,71 \cdot 3$ & 6 & 43 & 2 & 14 \\
\hline Non-Caucasian & 14 & $34 \cdot 0$ & $17 \cdot 5,45$ & 12 & 86 & 5 & 36 \\
\hline Total summer & 28 & $42 \cdot 5$ & $24 \cdot 3,63$ & 18 & 64 & 7 & 25 \\
\hline \multicolumn{8}{|l|}{34 weeks } \\
\hline \multicolumn{8}{|l|}{ Winter } \\
\hline Caucasian & 28 & $61 \cdot 0$ & $35 \cdot 8,84 \cdot 8$ & 11 & 39 & 4 & 14 \\
\hline Non-Caucasian & 32 & 57.5 & $21 \cdot 3,75 \cdot 5$ & 15 & 47 & 9 & 28 \\
\hline Total winter & 60 & $58 \cdot 5$ & $26 \cdot 5,80 \cdot 3$ & 26 & 43 & 13 & 22 \\
\hline \multicolumn{8}{|l|}{ Summer } \\
\hline Caucasian & 16 & $70 \cdot 0$ & $44 \cdot 5,95 \cdot 3$ & 5 & 31 & 1 & 6 \\
\hline Non-Caucasian & 25 & $77 \cdot 0$ & 53,97 & 5 & 20 & 0 & \\
\hline Total summer & 41 & $73 \cdot 0$ & $49 \cdot 5,95 \cdot 5$ & 10 & 24 & 1 & 2 \\
\hline
\end{tabular}

* Summer is defined as April to September and winter is defined as October to March.

†Percentage by ethnic group.

Infant birth weight was weakly inversely associated with PCV concentrations at 26 weeks of gestation $(P=0 \cdot 024 ; r-0 \cdot 126)$.

\section{Discussion}

The present study demonstrated that multiple-micronutrient supplementation from the first trimester improved micronutrient status in later pregnancy, in this low-income, multi-ethnic population. Markers of $\mathrm{Fe}$, folate, thiamin and vitamin $\mathrm{D}$ status were all higher during the third trimester for those receiving the supplement relative to the placebo group. Poor nutrient status during pregnancy and adverse obstetric outcome have been consistently seen throughout pregnancy in this population ${ }^{(3)}$.

Although the non-compliance rate was high, it is comparable with that seen previously in this population and reflects a lack of interest in health and poor knowledge of the relationship between nutrition and pregnancy outcome ${ }^{(13)}$. One potential issue of the supplements is the formulation; thirtyone participants ( $8 \%$ of all participants) ceased the study as they disliked the formulation of the supplements, the majority finding them too large to swallow. However, despite the low compliance, the treatment showed significant improvement in nutrient status relative to the placebo.

Considering only the participants who were compliant throughout the study, the supplement appeared to reduce the numbers of SGA infants. However, this was not seen using intention-to-treat analysis or only for women recruited before 13 weeks of gestation and will need further verification with much larger studies. Also there were weak associations between nutrient status and birth outcome. However, the present study was powered to investigate the effect of multiple-micronutrient supplementation on birth weight; thus a limitation of the results presented here is that the study was not powered to investigate effects on micronutrient status or other birth outcomes.

The prevalence of low $\mathrm{Fe}$ status at recruitment in the present study was similar to a previous Hackney study (9\% anaemic and $10 \%$ low Fe stores) ${ }^{(4)}$. Hb and PCV concentrations are known to decrease from the first to the third trimester and increase slightly at term ${ }^{(14)}$; this trend was clearly seen in the present study, however, the decrease was greatest for women receiving the placebo. Serum ferritin usually decreases as pregnancy advances ${ }^{(15)}$. In the present 
study as pregnancy progressed the number of participants with low $\mathrm{Fe}$ stores increased; however, this increase was less for supplemented women.

Research suggests that even women with good Fe status may benefit from low-dose Fe supplementation during pregnancy. Daily supplementation of Fe-replete women with $30 \mathrm{mg}$ Fe from mid-pregnancy reduced the incidence of LBW and preterm birth ${ }^{(16)}$. The current supplement provided $20 \mathrm{mg}$ Fe per d, higher than the UK reference nutrient intake (RNI) of $14.8 \mathrm{mg} / \mathrm{d}^{(17)}$ but much lower than commonly prescribed during pregnancy (up to $300 \mathrm{mg} / \mathrm{d}$ ). Patients often show poor compliance with high-dose Fe supplements, thought to be a result of gastric side effects such as heartburn, nausea, vomiting, constipation and diarrhoea ${ }^{(18)}$. Similar numbers of women from both groups (twenty in the treatment group $v$. twenty-two in the placebo group) ceased the present study due to reported gastric side effects; these were most likely symptoms of pregnancy rather than actual side effects. Similarly Makrides et al. ${ }^{(19)}$ found that women supplemented with $20 \mathrm{mg}$ Fe daily from 20 weeks of gestation until delivery had improved $\mathrm{Fe}$ status with no difference in gastrointestinal side effects compared with the placebo group. Further Zhou et $a{ }^{(20)}$ demonstrated a daily dose of $20 \mathrm{mg}$ elemental $\mathrm{Fe}$ during pregnancy resulted in reduced occurrence of nausea, stomach pain and vomiting compared with 40 or $80 \mathrm{mg} \mathrm{Fe}$ with no difference in the incidence of anaemia.

The prevalence of folate deficiency at recruitment within the study population has been discussed previously ${ }^{(9)}$ and is similar to the prevalence of deficiency seen in non-pregnant women in the UK National Diet and Nutrition Survey $(\mathrm{NDNS})^{(21)}$. The supplement provided the recommended $400 \mu \mathrm{g}$ folic acid per $\mathrm{d}^{(22)}$ and as pregnancy progressed mean erythrocyte folate concentration increased amongst those using the supplement; however, those receiving the placebo showed a decrease in folate status as pregnancy advanced.

In the present study $12 \%$ of participants were thiamin deficient during the first trimester, much higher than the $1 \%$ of women seen in the NDNS ${ }^{(21)}$. The present treatment provided $3 \mathrm{mg}$ thiamin/d, which is higher than the $\mathrm{RNI}^{(17)}$ of $0.8-0.9 \mathrm{mg} / \mathrm{d}$, but is not excessive compared with the US $\mathrm{RDA}^{(23)}$ of $1.4 \mathrm{mg} / \mathrm{d}$ with no toxic level of intake defined. By 34 weeks of gestation participants using the supplement showed a non-significant increase in thiamin status. The proportion of women who were thiamin deficient increased in later pregnancy; however, this increase was less for the treatment group.

There is much debate surrounding the appropriate cut-off for optimal vitamin D status. Deficiency is typically defined as 25 -hydroxyvitamin $\mathrm{D}<25 \mathrm{nmol} / \mathrm{l}^{(24)}$; however, Malabanan et $a .^{(12)}$ advocate $<50 \mathrm{nmol} / \mathrm{l}$ as insufficiency. Using these cut-offs in the present study levels of deficiency were 27, 22 and $14 \%$ and levels of insufficiency were 70, 52 and $36 \%$ at recruitment, 26 and 34 weeks of gestation, respectively, with a median concentration of $37.5,47.0$ and $62.0 \mathrm{nmol} / \mathrm{l}$ at each time-point. Using the same cut-offs, Holmes et al. ${ }^{(25)}$ found lower status among pregnant women in Northern Ireland, with levels of deficiency of 35, 44 and $16 \%$ and levels of insufficiency of 96,96 and $75 \%$ at 12,20 and 35 weeks of gestation. The present study shows considerable insufficiency amongst this multi-ethnic population which could result in adverse $\mathrm{Ca}$ handling for both mother and fetus. The major source of vitamin D is from sun exposure; however, highly pigmented skin is less effective at producing vitamin $\mathrm{D}^{(26)}$. Also some ethnic groups restrict exposure to sunlight by covering up with clothing for cultural or religious reasons. Further, in the UK there is no appropriate UVB radiation between the end of October and the end of $\operatorname{March}^{(17)}$. In the present study blood samples were collected throughout the year, which should minimise the effect of season on differences between treatment and placebo, although any effect cannot be ruled out.

The supplement provided $5 \mu \mathrm{g}$ cholecalciferol (vitamin $\mathrm{D}_{3}$ ) per $d$, half of the RNI during pregnancy ${ }^{(24)}$; this appears to have improved vitamin D status. Hollis \& Wagner ${ }^{(27)}$ argue that the current recommendations are insufficient and the appropriate dose could be as high as $250 \mu \mathrm{g} / \mathrm{d}$. Hollis \& Wagner $^{(28)}$ have demonstrated that high doses of vitamin D $(100$ or $50 \mu \mathrm{g} / \mathrm{d})$ given to lactating women improve vitamin $\mathrm{D}$ status without adverse effects. Mannion et al. ${ }^{(29)}$ demonstrated in Canada at $51^{\circ} \mathrm{N}$ (the same latitude as Southern England) that dietary intake of vitamin D during pregnancy was a significant predictor of infant birth weight. The Royal College of Obstetricians and Gynaecologists and the National Institute for Health and Clinical Excellence suggest that it may be advisable for pregnant women to be supplemented daily with $10 \mu \mathrm{g}$ vitamin $\mathrm{D}^{(30,31)}$; however, there is still a lack of awareness of the need for vitamin D during pregnancy ${ }^{(32)}$. In the present study the only significant effect of treatment was at 26 weeks; the lack of a consistent effect could result from the supplement providing insufficient vitamin $\mathrm{D}$ for a population of such low status. It was not possible to establish the effects of ethnicity and season due to the small number of samples. Further work is required investigating vitamin D requirements during pregnancy, especially for different ethnic groups, in the light of recent studies suggesting the inadequacy of current recommendations and the relationship between status and birth outcome.

\section{Conclusions}

The present study showed that prophylactic use of a multiplemicronutrient supplement from the first trimester improved nutrient status, for measures of $\mathrm{Fe}$, folate, vitamin $\mathrm{D}$ and thiamin, amongst a socially deprived, multi-ethnic population. It also adds weight to the argument that treatment with prophylactic low-dose $\mathrm{Fe}$ supplements may be preferable to using high doses for improving Fe status during pregnancy. The present study further suggests that such supplementation may improve fetal growth but further larger studies are required to corroborate these results, especially amongst disadvantaged populations within developed countries.

\section{Acknowledgements}

The study was supported with funding provided by the Mother and Child Foundation (http://www.motherandchildfoundation. org/). The multiple-micronutrient supplement and placebo tablets were manufactured and provided by Vitabiotics (London, UK). Funding for vitamin D analysis was provided by Nutricia Research Foundation (http://www.nutriciaresearch-foundation.org/). 
The present study was carried out jointly by the Institute of Brain Chemistry and Human Nutrition (London Metropolitan University, London, UK) and Homerton University Hospital (London, UK).

L. B., G. A. R., M. A. C. and E. K. D. designed the study. L. B. and G. A. R. recruited participants and collected data. L. B. analysed the data and R. H. M. provided statistical advice. All authors contributed to the writing and reviewing of the paper and approved the final version.

L. B. and G. A. R. were formerly affiliated to London Metropolitan University.

There are no conflicts of interest.

\section{References}

1. Scholl TO (2008) Maternal nutrition before and during pregnancy. Nestle Nutr Workshop Ser Pediatr Program 61, 79-89.

2. Kramer MS, Seguin L, Lydon J, et al. (2000) Socio-economic disparities in pregnancy outcome: why do the poor fare so poorly? Paediatr Perinat Epidemiol 14, 194-210.

3. Doyle W \& Rees G (2001) Maternal malnutrition in the UK and low birthweight. Nutr Health 15, 213-218.

4. Rees G, Brooke Z, Doyle W, et al. (2005) The nutritional status of women in the first trimester of pregnancy attending an inner-city antenatal department in the UK. $J R$ Soc Health 125, 232-238.

5. Rees GA, Doyle W, Srivastava A, et al. (2005) The nutrient intakes of mothers of low birth weight babies - a comparison of ethnic groups in East London, UK. Matern Child Nutr 1, 91-99.

6. Haider BA \& Bhutta ZA (2006) Multiple-micronutrient supplementation for women during pregnancy. Cochrane Database Syst Rev CD004905. The Cochrane Database of Systematic Reviews 2006, issue 4, CD004905. http://www. mrw.interscience.wiley.com/cochrane/clsysrev/articles/CD0049 05/frame.html

7. Scholl TO, Hediger ML, Bendich A, et al. (1997) Use of multivitamin/mineral prenatal supplements: influence on the outcome of pregnancy. Am J Epidemiol 146, 134-141.

8. Hininger I, Favier M, Arnaud J, et al. (2004) Effects of a combined micronutrient supplementation on maternal biological status and newborn anthropometrics measurements: a randomized double-blind, placebo-controlled trial in apparently healthy pregnant women. Eur J Clin Nutr 58, 52-59.

9. Brough L, Rees GA, Crawford MA, et al. (2009) Social and ethnic differences in folic acid use preconception and during early pregnancy in the UK: effect on maternal folate status. J Hum Nutr Diet 22, 100-107.

10. World Health Organization, United Nations Children's Fund \& United Nations University (2001) Iron Deficiency Anaemia Assessment, Prevention, and Control. A Guide for Programme Managers. Geneva: WHO.

11. Sauberlich HE, Dowdy RP \& Skala JH (1973) Laboratory tests for the assessment of nutritional status. CRC Crit Rev Clin Lab Sci 4, 215-340.

12. Malabanan A, Veronikis IE \& Holick MF (1998) Redefining vitamin D insufficiency. Lancet 351, 805-806.

13. Doyle W, Crawford MA, Srivastava A, et al. (1999) Interpregnancy nutrition intervention with mothers of low-birthweight babies living in an inner city area: a feasibility study. J Hum Nutr Diet 12, 517-527.
14. Scholl TO (2005) Iron status during pregnancy: setting the stage for mother and infant. Am J Clin Nutr 81, 1218S-1222S.

15. Kaufer M \& Casaneuva E (1990) Relation of pregnancy serum ferritin levels to hemoglobin levels throughout pregnancy. Eur $J$ Clin Nutr 44, 709-715.

16. Cogswell ME, Parvanta I, Ickes L, et al. (2003) Iron supplementation during pregnancy, anemia, and birth weight: a randomized controlled trial. Am J Clin Nutr 78, 773-781.

17. Department of Health (1991) Dietary Reference Values for Food Energy and Nutrients for the United Kingdom. Report on Health and Social Subjects no. 41. London: H.M. Stationery Office.

18. Beard JL (2000) Effectiveness and strategies of iron supplementation during pregnancy. Am J Clin Nutr 71, 1288S-1294S.

19. Makrides M, Crowther CA, Gibson RA, et al. (2003) Efficacy and tolerability of low-dose iron supplements during pregnancy: a randomized controlled trial. Am J Clin Nutr 78, $145-153$

20. Zhou SJ, Gibson RA, Crowther CA, et al. (2009) Should we lower the dose of iron when treating anaemia in pregnancy? A randomized dose-response trial. Eur J Clin Nutr 63, 183-190.

21. Ruston D, Hoare J, Henderson L, et al. (2004) National Diet and Nutrition Survey: Adults Aged 19 to 64 Years. Volume 4: Nutritional Status (Anthropometry and Blood Analytes), Blood Pressure and Physical Activity. London: The Stationery Office.

22. Department of Health (2000) Folic Acid and the Prevention of Disease. Report on Health and Social Subjects no. 50. London: The Stationery Office.

23. Institute of Medicine (2006) Dietary Reference Intakes: the Essential Guide to Nutrient Requirements. Washington, DC: National Academies Press.

24. Department of Health (1998) Nutrition and Bone Health: With Particular Reference to Vitamin D. Report on Health and Social Subjects no. 49. London: H.M. Stationery Office.

25. Holmes VA, Barnes MS, Alexander HD, et al. (2009) Vitamin $D$ deficiency and insufficiency in pregnant women: a longitudinal study. Br J Nutr 102, 876-881.

26. Matsuoka LY, Wortsman J, Haddad JG, et al. (1991) Racial pigmentation and the cutaneous synthesis of vitamin D. Arch Dermatol 127, 536-538.

27. Hollis BW \& Wagner CL (2004) Assessment of dietary vitamin $\mathrm{D}$ requirements during pregnancy and lactation. Am J Clin Nutr 79, 717-726.

28. Hollis BW \& Wagner CL (2004) Vitamin D requirements during lactation: high-dose maternal supplementation as therapy to prevent hypovitaminosis $\mathrm{D}$ for both the mother and the nursing infant. Am J Clin Nutr 80, 1752S-1758S.

29. Mannion CA, Gray-Donald K \& Koski KG (2006) Association of low intake of milk and vitamin D during pregnancy with decreased birth weight. CMAJ 174, 1273-1277.

30. National Collaborating Centre for Women's and Children's Health (2008) Antenatal Care: Routine Care for the Healthy Pregnant Woman: CG62. London: RCOG Press.

31. National Institute for Health and Clinical Excellence (2008) Guidance for Midwives, Health Visitors, Pharmacists and Other Primary Care Services to Improve the Nutrition of Pregnant and Breastfeeding Mothers and Children in Low Income Households. London: National Institute for Health and Clinical Excellence.

32. Sharma S, Khan N, Khadri A, et al. (2009) Vitamin D in pregnancy - time for action: a paediatric audit. BJOG 116, $1678-1682$. 